\title{
أثر اختلاف مفهوم القيم والأخلاق العامة في تحديد نوعية القوانين والحقوق: دراسة مقارنة بين الدول الغربية والدول الإسلامية
}

\author{
د. أحمد صلاح الدين بالطو \\ أستاذ مساعد في قسم القانون العام - كلية الحقوق \\ جامعة الملك عبد العزيز
}

مستخلص. تقوم هذه الدراسة باستعراض القيم الأخلاقية المختلفة في الدول الإسلامية والغربية، وذلك من خلال

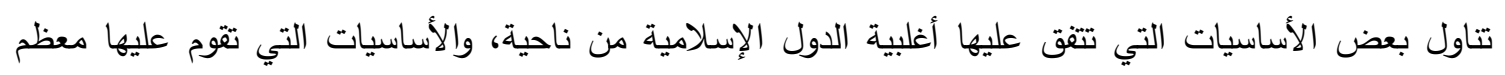
الدول الغربية من ناحية أخرى. الهدف من ذلك هو محاولة الوصول إلى السبب الحقيقي وراء اختلاف القوانين والحقوق الممنوحة في الدول الإسلامية والغربية. إن دراسة المنظومة الأخلاقية والقيمية العامة للمجتمع الإسلامي

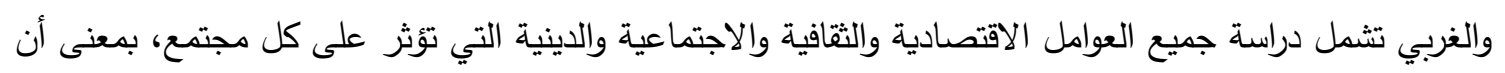
مجموع هذه العوامل يؤسس نظام أخلاقي عام، يتم من خلاله تطبيق وتفسير القوانين والحقوق في الواقع العملي.

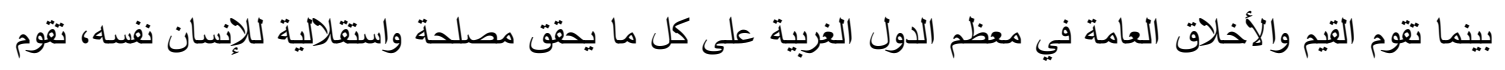
المنظومة الأخلاقية العامة في معظم الدول الإسلامية على أحكام الدين الإسلامي ومبادئه. فمن ناحية، تقوم هذه الدراسة بتحليل بعض السياقات التاريخية للدول الغربية التي ساهمت بشكل كبير في تحول تركيز المنظومة الأخلاقية من الدين المسيحي إلى الإنسانية والعلمانية والعقلانية البحتة. ومن ناحية أخرى، تقوم الدراسة بالتأكيد

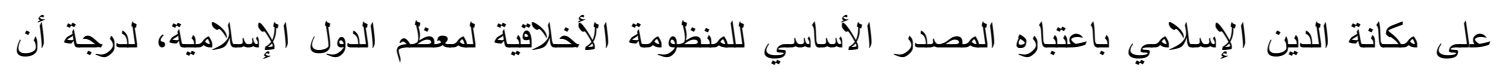
الإخلال بتعاليم الدين الإسلامي يؤدي بالضرورة إلى الإخلال باستقرار المجتمع داخل الدول الإسلامية.

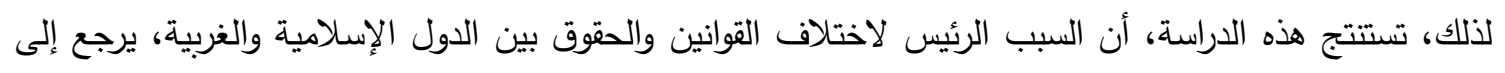
اختلاف القيم والأنظمة الأخلاقية لكلاً منهما، والتي تؤثر بشكل كبير في طبيعة ومضمون هذه القوانين والحقوق. بينما تمنح المنظومة الأخلاقية الإسلامية الحريات التي تتوافق مع تعاليم ومبادئ الثريعة الإسلامية والمجتمع توني المسلم، تعترف المنظومة الأخلاقية الغربية بأي نوع من الحريات لمجرد أنها تزيد من حرية الفرد واستقلاله، حتى لو لو كان ذلك على حساب الدين أو المجتمع.

مشروعاً يتم بموجبه تحديد مضمون الحقوق والقوانين المقدمة حسابة الب المنا

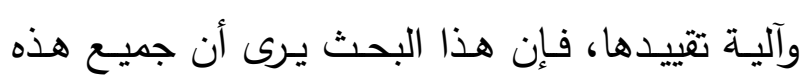
المسائل تتحدد في النهاية بحسب الأخلاقيات العامة
بـالرغم مـن اعتـراف الشــريعة الإســلامية وحقـوق الإنسـان الدوليـة بـالأخلاق العامـة للمجتمـع أساسـاً 
السياسية قد تظل غير مقبولة لديهم، لأنهم يعتقدون أن أفضـل طريقـة لمعـاملتهم هـي المنطق الإنسـاني وليس التشريح الإلهي. على الجانـب الآخـر، فـإن المصـــر الشـامل للقيم الإســلامية - الدين - يـؤثر في الأخلاقيـات العامـة للدول الإسـامية. ويبدو هذا واضحاً، ليس فقط في رفض الفصـل بـين الدين والدولـة، وإنمـا أيضـاً في حقيقة أنه "لا يوجد نشاط يمكن اعتباره علمانياً بحتاً في حياة المسلم." وبينمـا ترتكز الدول الإسـلامية (والأخلاقيـات العامـة للدول الإسـامية) على الإيمان بالدين الإسلامي، فإن الدول الغربية وأخلاقياتها العامـة قد تحولت وجهتها عـن الــدين إلــى العلمانيــة الإنســانية والعقلانيــة. وسيتضـــح أن الــدين لــيس مكونــاً أساسـياً فــي الأخلاقيات العامسة لأغلب المجتمعات الغربيـة، لأن مفهـوم الليبراليــة ومفهـوم لغـــة الحقـوق، يرتبطــان بـالهروب مـن الأحكـام الدينيـة. ‘ لـذلك، ففـي تلـك الـدول، نجد أن السـماح للدين بـأن يكـون مـن أهـم

" محمد الزحيلي، حقوق الإنسان في الإسلام: دراسة مقارنة مع الإعلان العالمي

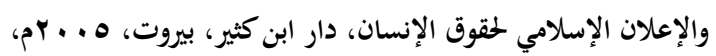

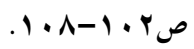

M. Y. Rathor and others, 'Is Autonomy a Universal Value of Human Existence? Scope of Autonomy in Medical Practice: a Comparative Study between Western Medical Ethics and Islamic Medical Ethics' (2016) 15 (1) International Medical Journal Malaysia 81, 84. ' ساجر ناصر الجبوري، حقوق الإنسان السياسية في الإسلام والنظم العالمية،

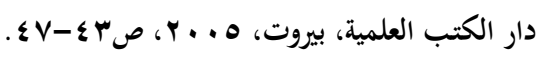

المختلفــة لكـل مجتمـعـ.' هــذه الأخلاقيـات العامــة تخضع لمختلف العوامل الثقافية والبيئية، منها العائلة والقبيلة، والنظم السياسية، التي تشكل جميعها أدوار الأفراد داخل المجتمعات. ومن المؤكد أن الأعراف الاجتماعيـة والممارسـات المحلية مهمـة للفرد، لدرجـة أنه "عند توصل الفرد لأي رؤيـة لنفسه، فإنه يفكر في هويتهـ، باعتبارهـا تتحـد بانتمائـه للجماعـة والأدوار

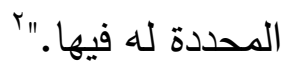
لذلك، يقال: إن كل مجتمع له أخلاقيات عامـة تتمثل في شبكة متصلة، واحترام ضروري لاستقرار المجتمع ذاتـه، بحيـث لا يمكـن التسـامح مـع الانحـراف في الجوانـب الدينيــة والاجتماعيـة دون تعـريض هيكل المجتمع نفسه للخطر • أن

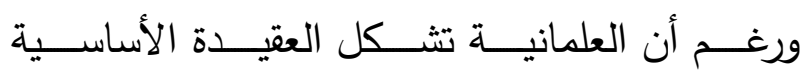

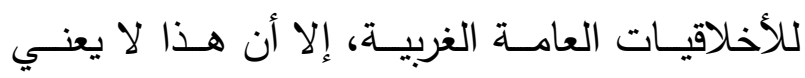
بالضرورة أن الدين ينبغي أن يستبعد دوماً من المناخ العـام. بـلـل إن ذلـك يعنـي أن الأخلاقيـات العامــة للمجتمعات الغربية العادية لا تشمل الدين، من واقع أنـه جزء أساسـي مـن تلك الأخلاقيات. وحتى فيما يتعلق ببعض الأفراد المتدينين، نجد أن فكرة وجوب سـيطرة الـدين علـى القـوانين والحقـوق والكيانـات ' عبد اللطيف بن سعيد الغامدي، حقوق الإنسان في الإسلام، أكاديمية نايف

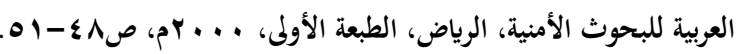
Joel Feinberg, The Moral Limits of the Criminal ${ }^{r}$ Law: Harmless Wrongdoing (Vo. 4, Oxford University Press, 1990) 82-84.

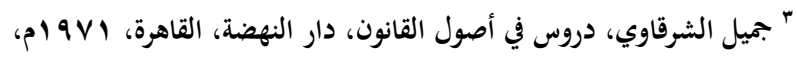

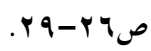


حيث تتجلى بـأن اختلاف مفـاهيم الأخـاق العامـة

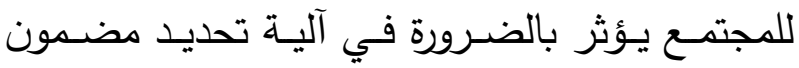

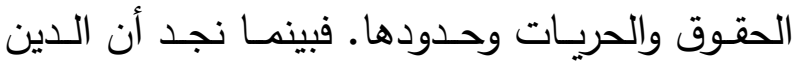

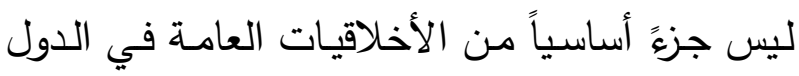

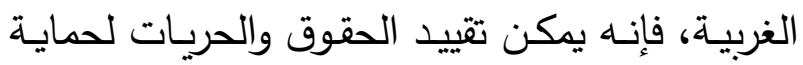
الفرد وليس الدين، لأن نقطة انطلاق هذه الحقوق لفي

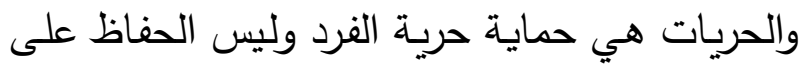

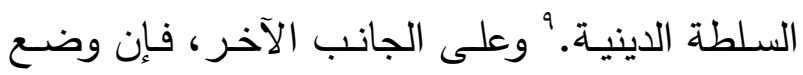
الدين الإسـلامي، لكونه حجر زاوية في الأخلاقيات

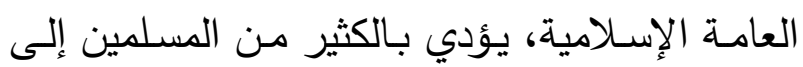

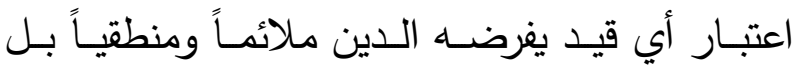
وواجباً. '1 أن

وعلى الرغم من أن تحديد مضمون الحقوق والحريات

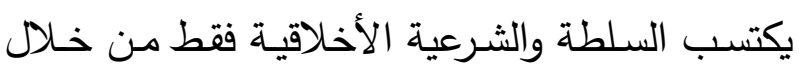

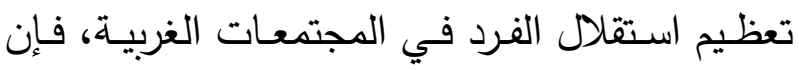
المجتمعات الإسلامية تقبل الحقوق والحريات فقط إذا

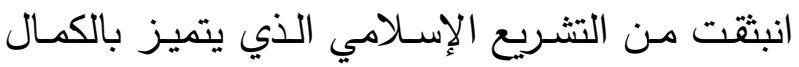

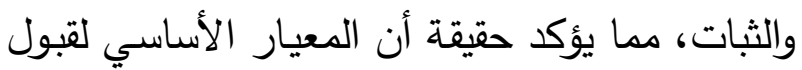

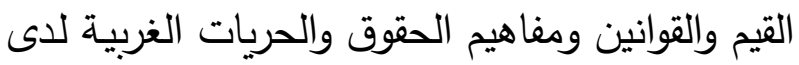

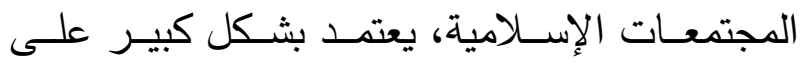

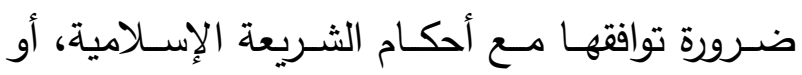

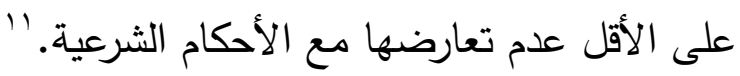
9 منير حميد البياتي، النظام السياسي الإسلامي مقارنة بالدولة القانونية، دار

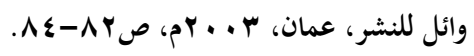
•" مفرح سليمان القوسي، حقوق الانسان في مجال الأسرة من منظور إسلامي،

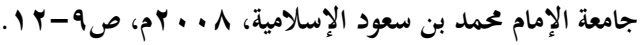
" يسري السيد محمد، حقوق الإنسان في ضوء الكتاب والسنة، دار المعرفة

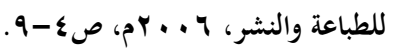

أجزاء ومقومـات الأخلاقيـات العامـة، يعد أمـراً غير أخلاقي في حد ذاته. عـلاوة على ذلك، فإن التنوير عزز من تفوق المنطق العقلي على الدين: فإذا كان

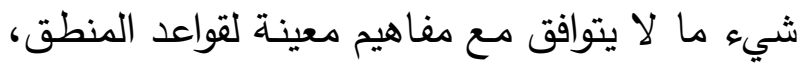
فإنه يعد غير ملأئ.

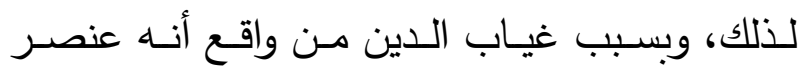
أساسـي في الأخلاقيـات العامـة الغزبيـة، وبقدر عدم إمكانية إدراك بعض القواعد الدينية باستخدام المنطق

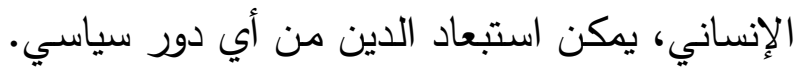

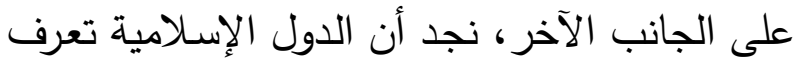

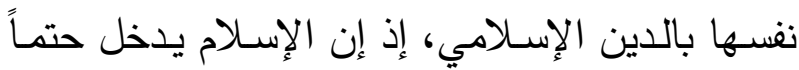

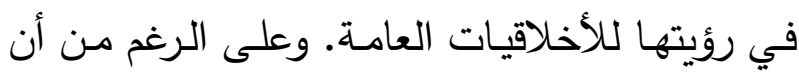
مختلف المجتمعات الإسلامية لها رؤى مختلفة بشأن حدود دور الدين الإسـالامي في الأخلاقيات العامـة،

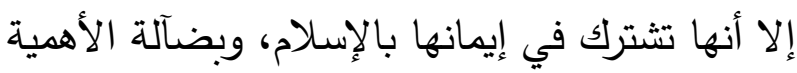
النسبية للفردية، مقارنة بأهمية الدين الإسلامي. أهمية البحث

إن أهيــة استكثــاف هـــه الفروقـات فـي مفهـوم

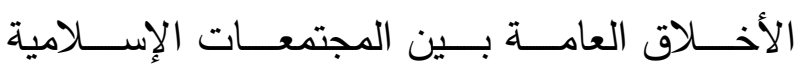
والمجتمعـات الغربيـة، توضـح الأسـباب التي تكمـن

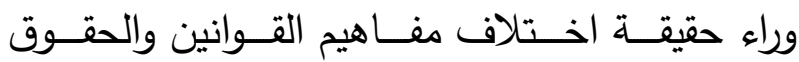
والحريات الموجودة في العالمين الإسـامي والغربي، " عحمد فتحي عثمان، حقوق الإنسان بين الشريعة الإسلامية والفكر القانوفي

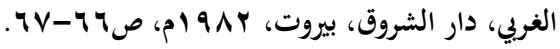

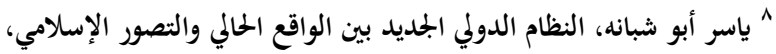

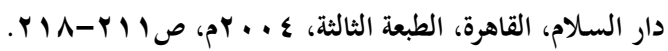


والقواعد الأخلاقية في ظل الثقافة الغربية، وتطبقها الدول الإسـلامية من خـلال ثقافة تسود فيها أحكام الشريعة الإسلامية. با هذا الاختلاف في الثقافات هو السـبب الأسـاسـي لاختـلاف تطبيـق القيم والأخـلاق داخـل كـل أيديولوجيـة: ففي حـين ينـتهج الإعـلان

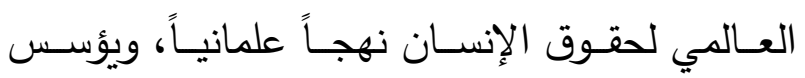
الحقوق على أسـاس النظرة الإنسـانية فقط، نجد أن الشريعة الإسلامية تقوم على أهمية الدين الإسلامي.

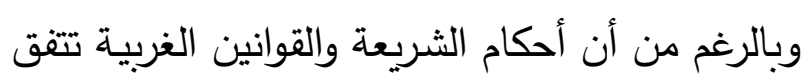
على إمكانيـة تقييـد الحقـوق والحريـات بنـاء على لى الأخـلاق العامـة للمجتمـع، فـإن هـذه المقولـة تقـوم بالتأكيد على أن سبب وجود الاختلاف في تطبيق حقوق الإنسان في العالمين الغربي والإسـلامي يعود إلـى حقيقــة وجـود اخـتلاف فـي مفهـوم الأخـلاق العامـة. ؛' بمعنى آخـر ، إن الفـروق الأساسـية بـين التشريعين الإسلامي والغربي ترجع في الأساس - إن إن لم يكن حصـرياً - إلى اختلاف تعريفـات الأخـلاق العامـة، وذلـك لأن عمليـة تطبيـق وتفسـير حقـوق الإنسان في الواقع العملي يتأثر بشكل كبير بمفهوم الأخلاق العامة السائدة في المجتمع.

r" سهيل حسين الفتلاوي، حقوق الإنسان في الإسلام: دراسة مقارنة في ضوء

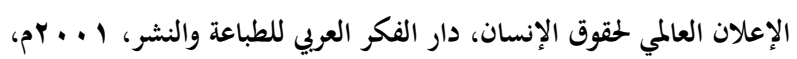
ص ص §' صلاح أحمد جودة، الحماية الدستورية والبرلمانية لحقوق الإنسان في الشريعة

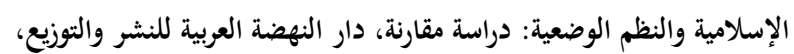

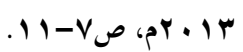
10 ساسي سالم الحاج، المفاهيم القانونية لحقوق الإنسان عبر الزمان والمكان،

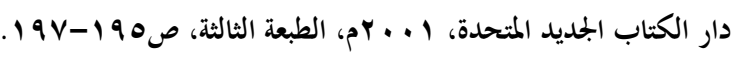

وعلى الـرغم مـن أن الأخلاقيـات العامـة للشـعوب

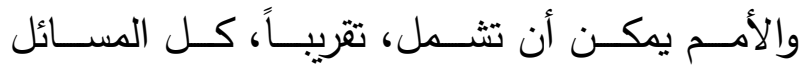
الاجتماعية والسياسية والشخصية المهمة التي يمكن أن تصـنع الفـروق في التوجهات الخاصـة بـالحقوق والحريات، إلا أن هذا لا يمنع من التأكيد على وجود عدة نقاط تتفق عليها المجتمعات الإسلامية والغربية، مثل الاتفــاق على اسـتخدام لغــة حقـوق الإنسـان، والاعتراف بالأخلاقيات العامة للمجتمع من واقع أنها أساس مهم لتحديد مضمون الحقوق والحريات. r' خطة ومنهج البحث

يتبع هذا البحث المنهج التحليلي المقارن، حيث يقوم البحث بتحليل العوامل المختلفة ذات الصلة بموضوع البحث في العالمين الإسـلامي والغربي. ويهدف هذا التحليل المقارن إلى الكثف عن الجوانب التي قد يكتنفها الغموض، مـن خـلال محاولـة الوصـول إلى فهم أعمق للموضوعات المتعلقة بمحل الدراسـة. وفي سـبيل تحقيـق هـذه الأهـداف، يستعين البحث بـآراء العديـد مـن الفقهـاء والعلمـاء الموجـودة في مؤلفـات علمية مكتوبـة باللغـة الإنجليزيـة والعربية لاستخلاص المبـادئ التي يقـوم عليهـا كـل مـن النظـام القـانوني الإسلامي والنظام القانوني الغربي. فالثريعة الإسلامية والقوانين الغربية، على الرغم من أنهــا يشـتركان في حمايـة بعض القواعد الأخلاقيـة المشـتركة، إلا أن الـدول الغربيـة تطبـق هـذه القـيم "ا عثمان أحمد عثمان، الكرامة الإنسانية وحقوق الإنسان في الفكر الإسلامي

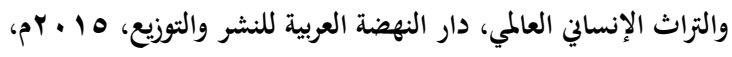
ص1 
كيفية اشتقاق ذلك التعريف.'1 لذلك، من غير الممكن أن تجد في القانون المحلي لمختلف الدول

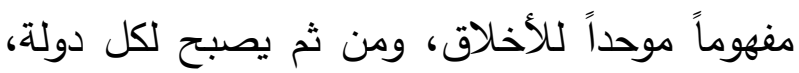

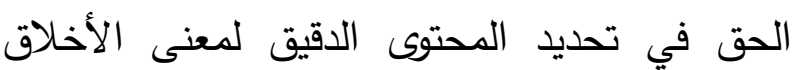

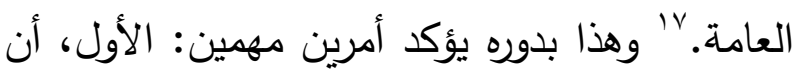
الأخلاق الاجتماعية قد تتغير حسب الوقت والمكان.

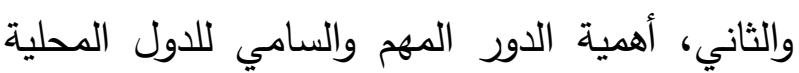
في تحديد مفهوم الأخلاق العامة لشعبها.

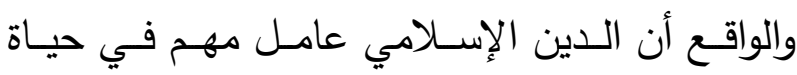
المسلم، مدـا يقتضـي الأخذ بعـين الاعتبـار تأثيره

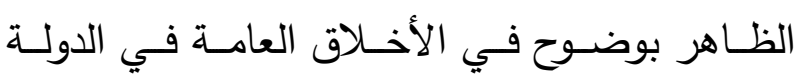

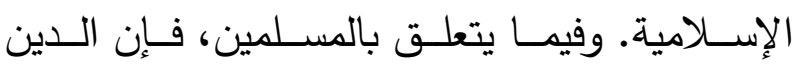

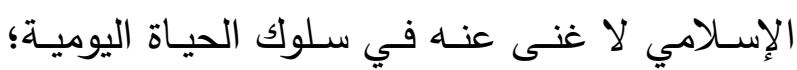

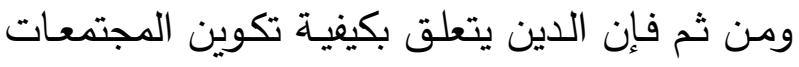

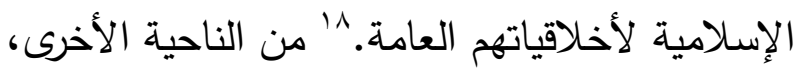

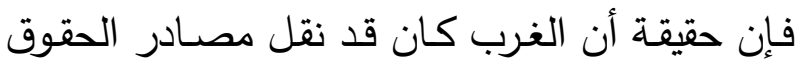
والقوانين من الدين المسيحي إلى الإنسان، فإن ذلك إنك يقتضي الأخذ في الاعتبار تداعيات هذا التغير ـ فإذا لـم يـتم الاحتكـام إلى الـدين عنــ تطـوير تعريفـات الأخلاقيات والنظام؛ فإنه يجب أن يوجد مصدر آخر تستقي منـه الحقوق والقوانين سلطتها، وإن تداعيات

"1 وليد محمد حمودة، القوانين الأساسية بين النظرية والتطبيق: دراسة مقارنة،

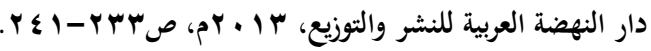

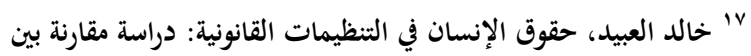
الشريعة الإسلامية والإعلانات والمواثيق الدولية، مكتبة الرشد، الطبعة الثانية،

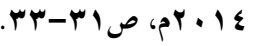

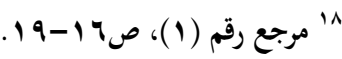

\section{نتائج البحث}

في سـياق تفسيرات الحقـوق والحريـات في العـالم

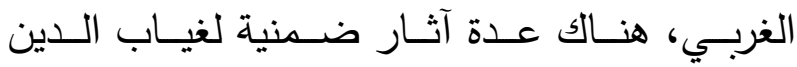
الإسـلامي، من واقع أنـه جانب أساسي للأخلاقيات

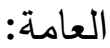
أولًا، بما أن الأخلاقيات العامة لا ترتكز على الدين،

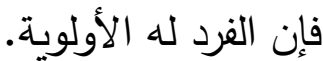
ثانيًا، بحكم عدم وجود نظام ديني أو عقائدي يحدد الاوله

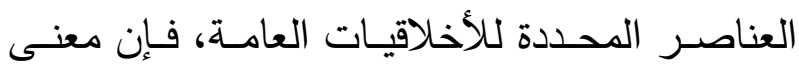

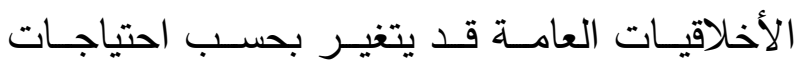

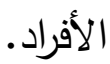

وعلى النقيض من ذلك، فإن وجود الدين الإسـلامي

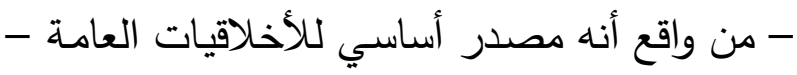
يؤثر في تحديد مضمون الحقوق والحريات في جانب

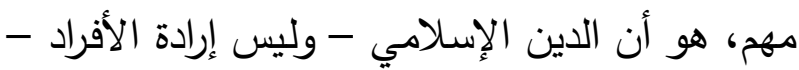
له الأولوية، ويجب هو ان للى الأفراد إنكار ذواتهم وتعطيل

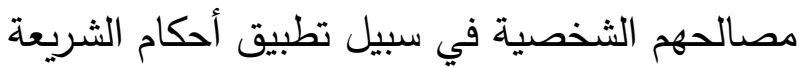

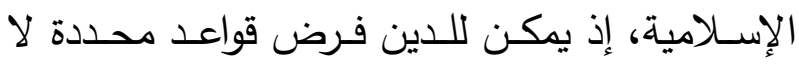
يمكن تغييرها أو تعديلها حتى مع مرور الزمن.

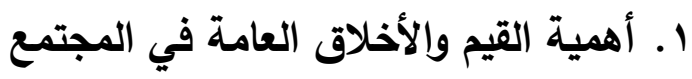
من الجدير بالذكر أنه يحق لكل أمة تحديد مفهوم الأخلاق العامة الخاص بها، بناء على ثثافتها وأوضاعها التاريخية، مما يؤكد إمكانية اختلاف لهاه مفهوم الأخلاق العامة من دولة إلى أخرى، بمعنى

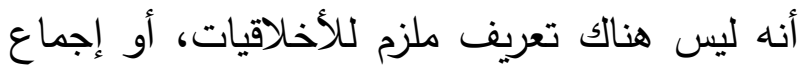
على العناصر التي تشكل معناها، أو اتفاق بشأن 
على ذلك القىع بسبب تعاظم سلطة الكنيسة والدور

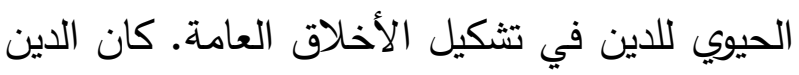

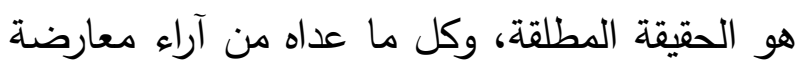

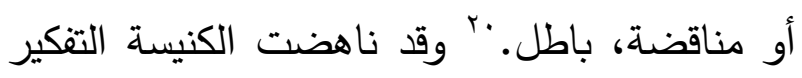
الناقد والاستقصاء العلمي في محاولة لـنع أية وناه مطالبات مضادة بالسلطة الاجتماعية. وقد أثرت هذه

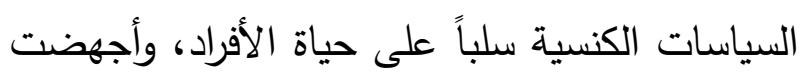
فرص التطور العلمي التي كان من شأنها أن تحسن وانس حياة البشر. وقد بدأ عصر التتوير - بشكل ما - في أوروبا في شكل رد فعل ضد السلطة الاقتصادية والسياسية للكهنوت والتعصب، المرتبطة بالحروب الرهيبة ذات

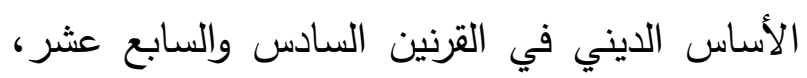
وذلك من أجل تحرير الأفراد من سيطرة الكنيسة.

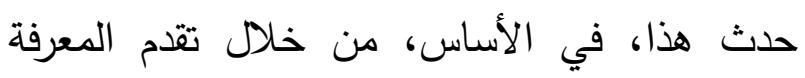
العلمية بشكل تحدى السلطة الدينية. ومع الوقت، هني، تقلصت مكانة الدين لاى الأفراد، بسبب ظهور الحكل العلم

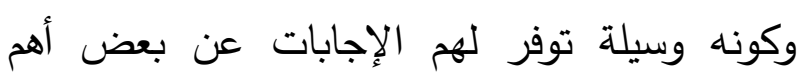

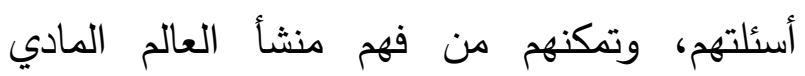
وطبيعته.r إن هذا التطور مهذ الطريق لظهور الإحاد، ولظهور أفراد يؤمنون بالدين إلا أنهم يرون

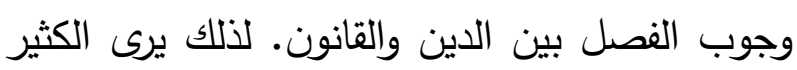

\section{Bertrand Russell, Why I am Not a Christian "}

(Simon and Schuster, 1957) 23-24.

"r محمد جمال عيسى، تاريخ القانون في الغرب، دار النهضة العربية للنشر

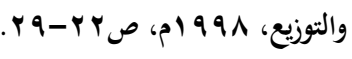

Jose Casanova, 'Private and Public Religions' ir

(1992) 59 (1) Social Research 17, 54-55.
هذا النقل يتجلى في توضيح آليـة وصـول الغرب لتحديد مفهوم الأخلاقيات العامة.

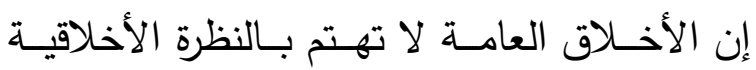
الشخصية للأفراد، لأن تلك النظرة تختلف اختلافاً كبيراً من فرد لأخر ، ولكن الأخـلاق العامـة تعكس لان تهـ

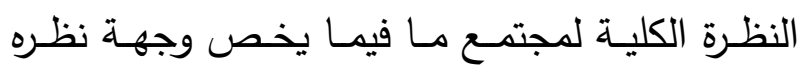

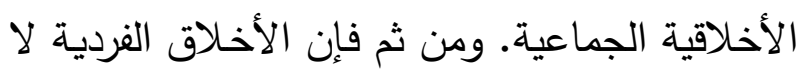

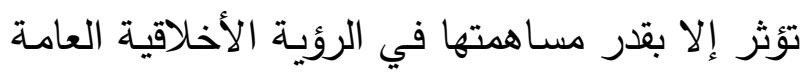

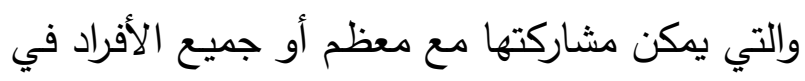
مجتمع ما. r , ا ـ القيم والأخلاق العامة في المجتمعات الغربية

ظلت المسيحية مسيطرة على تطور المجتمعات الغربية لحقب طويلة، ولم يكن الدين خلالها مجرد جزء من هيكل أكبر للأخلاقيات العامة؛ بل كان لان لان قانون الأرض: إذ كانت الكنيسة هي التي تتظم

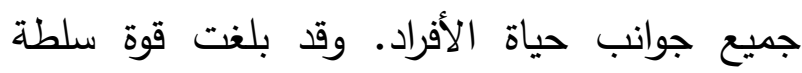

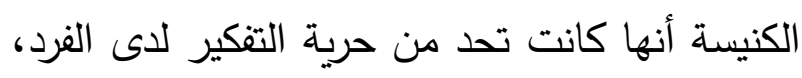
بل واتخاذ القرارات الخاصة بطريقة العيش. 19

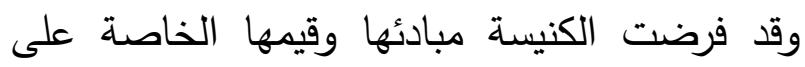
الأفراد وعلى المجتمع بشكل زاد من اعتمادهم على وضى ونى

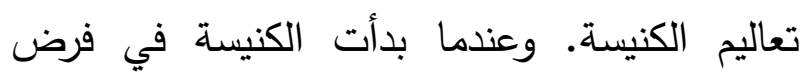
أيديولوجيتها الخاصة على الناس، بطريقة أدت إلى ولى لئل

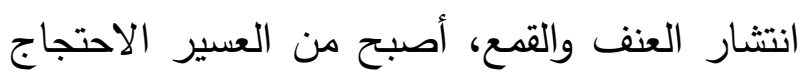

Robert Markus, Christianity and the Secular ${ }^{19}$ (University of Notre Dame Press, 2006) 15-18. 
كان لهذه التطورات أثر كبير في مكانة الدين من

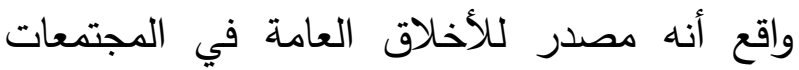
الغربية، مما أدى لتغيير رؤيتهم عن الدين. ويفنر "سيد نصر" أهم تغير فيما يتعلق بتحديد مفهوم لدئه الحقوق والحريات لاى المجتمعات الغربية، من خلال

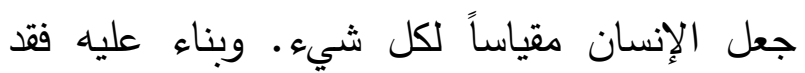
انتقل الدين من ضرورة إلى خيار، حسب الدنطق

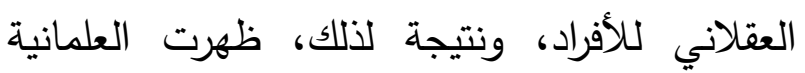

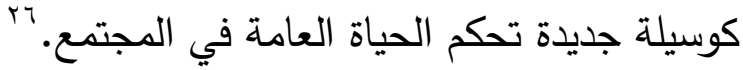
إن مفهوم العلمانية العقلانية كأساس للأخلاق العامة لدولة ما يتفق مع التعاليم البروتستانتية الليبرالية. هذه

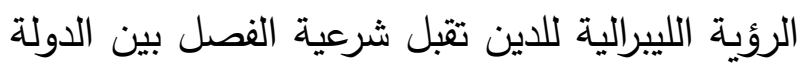
والكنيسة. ويفر بعض العلماء المسيحيين النصوص لئل

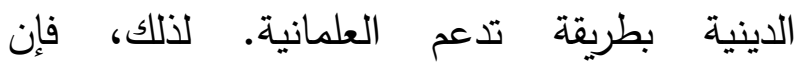

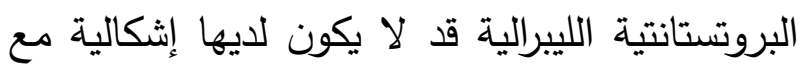

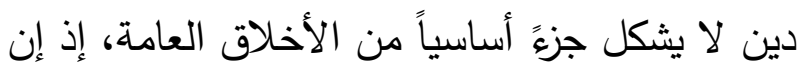
الدين يعد مسألة خاصة في الأساس، وعليه فإنها لهاسيه

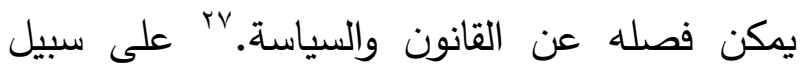
المثال، يرى "تشارلز لارمور" أن مفهوم الفصل بين ولني

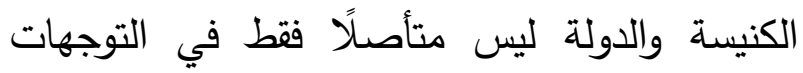
المسيحية، بل إنه يمثل "المنطق الداخلي للتوحيد

Seyyed Nasr, The Heart of Islam: Enduring "'

Values for Humanity (Harper One, 2002) 310. V رفيق عبد السلام، السياسة والدين في الغرب الحديث، مركز الجزيرة

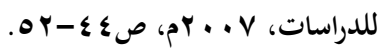

من علماء ومفكري الغرب أن عصر التوير قد شهد إنشاء إطار عل جديد للأفكار عن الإنسان والمجتمع والطبيعة، وهو إطار يتحدى المفاهيم القائمة المتجذرة في الرؤية التقليدية للعالم والتي هيمنت عليها المسيحية. وقد لخص "جرايمي سميت" التطورات التي ظهرت في عصر التوير في أربع نقاط: 1- صعود الرؤية الإنسانية، بما يشجع على اكتساب المعرفة والحكمة بطرق لا تتعلق بالسلطة الإلهية، كالتعلم من الآخرين، أو ربط الأمور بالعالم الطبيعي. ץ- ظهور النزعة القومية، وهي التي أعادت توجيه العواطف الموجهة سابقًا للكنيسة لتوجه إلى الأمم. س- الاختلافات اللاهوتية، وهي التي حدت من تأثير الدين، لأن كل كنيسة كانت لها تعاليمها

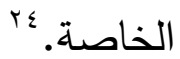
ع- الحروب الدينية، التي شجعت الناس على اتباع وسائل أقل عنفًا للسعي وراء المعرفة، مدا أدى إلى تطور العلم والمنطق.

rrr محمد مصباح عيسى، حقوق الإنسان في العالم المعاصر، دار الآفاق

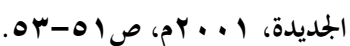

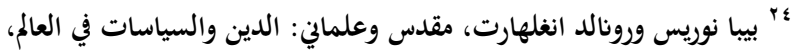

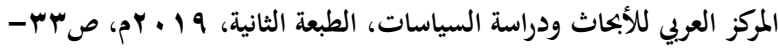

Graeme Smith, A Short History of Secularism to

(I.B. Tauris, 2008) 22-24. 
كما تعد الاعترافات الدينية امتهانًا لخصوصية المره، وتعدياً كذلك على حق الآخرين في الخصوصية."'ا" إن الفصل بين الدين والدولة، وخصخصة الدين، أثرا في معنى الأخلاق العامة في نقطة أساسية: لم يعد من الضروري توقير الدين في العالم الغربي. بمعنى آخر، أدى الإحلال التدريجي لاعتبارات الأداء الموضوعي والخبرة العملية محل تأثير الغيبيات والاعتبارات الأخلاقية لمجالات واسعة من الحياة العامة إلى تحول تمركز الأخلاق العامة من الدين إلى الفرد. r وعليه، حلت المؤسسات العلمانية محل الدين، وأصبح الفرد هو أهم عنصر في إنشاء معنى الأخلاق العامة. وكما يؤكد "نيفل كوكس"، فإن "الدين نفسه شيء لم يعد ذا أهمية كبرى للمجتمعات الغربية، بينما تعد حماية حرية الفرد الآن في مواجهة عدم التسامح الديني الواضح هي الأهم."r" نتيجة لذلك، ينبغي للأخلاق العامة أن تستجيب لاحتياجات المجتمع من أجل إنتاج مبادئ وقيم معينة تحمي رفاهية الفرد. ويمكن اعتبار رفاهية الفرد نقطة انطلاق يخرج ويترسخ منها معنى الأخلاق العامة في المجتمع الغربي. ترى "رودا هوارد" أن الأسلوب المتمحر

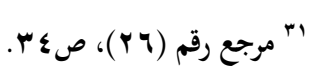

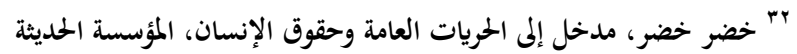

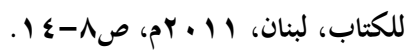

Neville Cox 'Blasphemy, Holocaust Denial, and ${ }^{r+}$ the Control of Profoundly Unacceptable Speech' (2014) 62 (3) The American Journal of Comparative Law 739, 757.

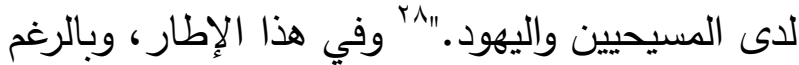
وبالرغم من أن "صدويل هنجتون" يرى أن المسيحية الغربية هي العنصر التاريخي الأهم في خصائص الحضارة الغربية، إلا أنه في الوقت نفسه يؤكد على أن "الرب وقيصر ، الدولة والكنيسة، السلطة الروحية

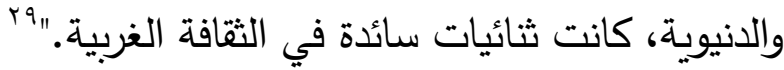
r , 1, ا ـ المذهب الفردي في المجتمعات الغربية إن أهمية الأفراد، والخوف المتزايد من الدين أدى كل منهما إلى موقف أكثر عدائية ضد الدين في الغرب. يرى "جوليان ريفرز" أن هذا العداء سبب نوعًا من "الانزلاق من القيد المؤسسي إلى الرفض العقلاني للدين بطريقة ظهرت كأنها محاولة لتحويل الدين إلى ألى مجرد هواية أخرى لها نفس القيمة الأخلاقية لجمع الطوابع أو رصد القطارات."·r" ويتقق معه "هوزيه كازانوفا" الذي يؤكد أن الدين لـ يفقد سلطته العامة فحسب، بل فقد أيضًا تقديسه لدى العامة. ويشرح ذلك بالقول: - - 1 "هذا التخصيص تمادى فعلياً حتى أصبح من "عدم الاحترام" و" قلة الذوق" أن تظهر تدينك على الملأ. Charles Larmore, 'Beyond Religion and ${ }^{\text {^ }}$ Enlightenment' (1993) 3 San Diego Law Review 799, 800-801. Samuel Huntington, The Clash of Civilizations ${ }^{\text {ra }}$ and the Remaking of the Modern World (Simon and Schuster, 1996) 70-71. Julian Rivers, 'The Secularization of the British ". Constitution' (2012) 14 Ecclesiastical Law Journal 371, 398. 
"أها جيمس كازانوفا" فيرى أن الغرب يعتبر (المنزل) المكان المناسب للدين في الحياة الاجتماعية، ويعرف المنزل بأنه "موطن الحب، والحميمية، والأهواء، والتعاطف، والعواطف، واللا عقلانية، والأخلاق

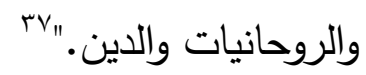

وبما أن الدين يستمد قوته من بناء مجتمع ديني يتشارك كل أعضائه في نظام أخلاقي معين، يرى "روي واليس" و"ستيف بروس" أن الانحدار الحاصل في المجتمعات الغربية في الرابطة بين الدين والمجتمع يؤدي بالضرورة إلى خصخصة الدين، إذ يقولان بأن الدين قد أصبح "تجربة فردية مخصصة، تنقل إلى هامش النظام الاجتماعي وتقاطعاته."A^r وعليه، أصبح الدين مسألة تفضيل ونشاط ترفيهي، وليس مسألة ضرورة. وهذا يعني أن المرو يمكنه الاختيار بين الأديان المتاحة، ويحاول أن يبني

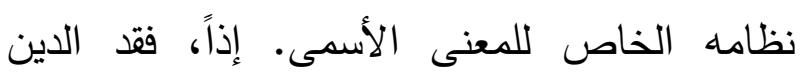
شرعيته كأحد جوانب الأخلاق العامة في المجتمعات الغربية، لأنه أصبح واقعاً خاصاً يخضع للأهواء الشخصية.

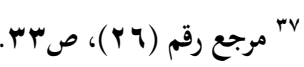

Roy Wallis and Steve Bruce 'Secularization: the ${ }^{i \wedge}$

Orthodox Model' in Steve Bruce. (ed.) Religion and Modernization: Sociologists and Historians Debate the Secularization Thesis (Clarendon Press, 1992) 13. a الاخسن حنفي وآخرون، حوار المشرق والمغرب: نصوص إضافية، منشورات

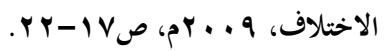

حول الفرد يؤدي إلى موقف "يتلاشى فيه الالتزام بالجماعة ورب الجماعة: ويقوى التزام المرء بنفسه

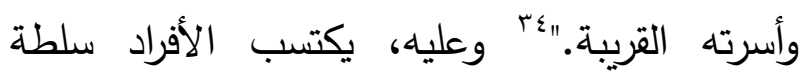
تحديد أساس الأخلاقيات العامة، ليس فقط بتوجيه الأخلاقيات العامة حسب فهمه الشخصي لها، بل أيضا بتغيير معنى الأخلاق العامة بحسب تغير

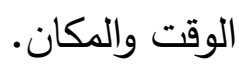
إن الأساس الذي يقوم عليه هذا المفهوم الفردي للأخلاق العامة هو أن الضمير مسألة فردية وليس مسألة كنسية أو مجتمعية. ويعني هذا أن وضع الأفراد داخل المجتمع يفوق من الناحية الأخلاقية قداسة التعاليم الإلهية للدين: التعبير عن الذات وإدراك الذات أصبحا الدين الخفي للحداثة. م بسبب هذا التفضيل للفرد على الدين، اضمحل الدور الاجتماعي للدين. ونتيجة لذلك أصبح الدين نظاماً فرعياً كالنظم الأخرى العادية وفقد هيمنته الراسخة. وحسب تعبير "جيمس بيكفورد" فإن "الدين في المجتمعات الصناعية المتقدمة قد فقد أو هجر وظيفته السابقة التي تمثلت في إعطاء الإحساس بالقيم السامية والثرعية للنظام الاجتماعي بأكمله."،r"

Rhoda Howard, 'Dignity, Community, and ${ }^{\text {rs }}$ Human Rights' in Abdullahi Ahmed An-Na'im (ed.) Human Rights in Cross-Cultural Perspectives: a Quest for Consensus (University of Pennsylvania, 1992) 92 .

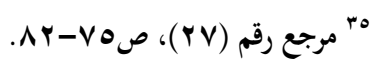

James Beckford, Social Theory and Religion ${ }^{m}$ (Cambridge University Press, 2003) 45. 
خارج إرادة الله سبحانه وتعالى. اء ولأن المجتمعات الإسلامية تقبل وجود الله وتؤمن بأنه يحميها، فقد أصبح الإسلام جزءً لا يتجزأ من الأخلاق العامة للمسلمين، إذ يعامل الإسلام الأخلاقيات على أنها هبة من الله سبحانه وتعالى. هذا الربط الكامن بين الله والأخلاق يقوم على الإيمان بأن الله قد خلق كل البشر، وكذلك عاداتهم وثقافاتهم المختلفة. ولذلك، يجب على البشر أن يعتمدوا على الله عز وجل في تحديد أفضل طريق لكي يعيشوا حياة مثرة أو أخلاقية، وينبغي أن تتحدد أخلاقية الأفعال حسب شرع الله. وفي عرف المسلمين، نجد أن توقير الله عز وجل أساسي وحتمي في تحديد السلامة الأخلاقية للأفعال، وليست هنالك بدائل لشرع الله. يشرح "سيد نصر" أن حياة المسلم تتضمن "التسليم لله في كل جوانب الحياة، واتباع الثرع الإلهي، والتعاليم الأخلاقية للإسلام بقدر المستطاع، والمجاهدة في الحياة حسب التعاليم الدينية بقدر قدرة المرو."rاء ويؤكد "نصر" كذلك أنه بعد التسليم الله، ينبغي للمرء

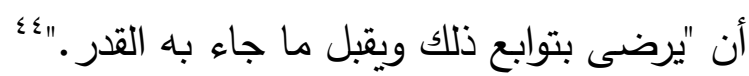
إن إيمان المجتمعات الإسلامية بالدين الإسلامي يؤثر في تشكيل أخلاقياتها العامة بطريقتين: الأولى،

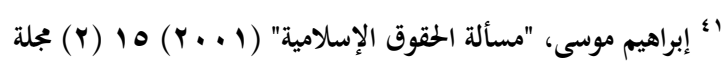

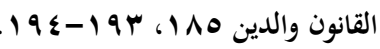

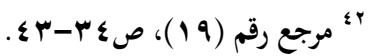

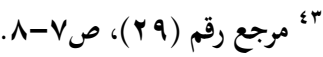

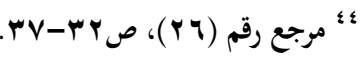

هذا الجزء من البحث يؤكد أن إقصاء الدين في العالم الغربي أدى في نهاية الأمر إلى تقديم العقلانية البشرية. وفي أغلب الدول الغربية، أصبح المحيط العام محجوزًا لكل ما يتم وصفه بأنه عقلاني وقابل للإثبات المادي، مما أدى إلى وضع أصبح الدين فيه قاصراً على المحيط الخاص، أو يسمح لله بالوجود في العام، ولكن دون أي أثر في القانون أو الأخلاق العامة. وهذا يدل على أن الدين لا يستحق الحماية في المجتمع، ولا يمكن أن يشكل مبرراً للحماية. بل إن الفرد، من واقع أنه كائن بشري، يستحق أن تتم حمايته حتى على حساب الدين. وعليه تصبح حماية الأفراد أمراً أساسياً في الأخلاق العامة الغربية. - ماتية Y, Y. القيم والأخلاق العامة في المجتمعات

\section{الإسـلامية}

إن نقطة انطلاق الأخلاق الإسلامية هي وجود الله سبحانه وتعالى، فالله عز وجل هو الخالق وسيد الوجود، ويؤمن المسلمون بأن كل ما على الأرض يعود إليه جل جالاله في النهاية، ويؤمنون أن الله قوة غير محدودة تتضاءل أمامها قدرة البشر. •؛ عند تطبيق تلك المعتقدات على كيفية بناء المسلمين لأخلاقهم العامة، يصبح واضحاً أن الأغلبية العظمى من المسلمين لا يحتمل أن يعتقدوا بوجود أي شيء

• ع عبد الحسين شعبان، الإسلام وحقوق الإنسان، بيسان للنشر والتوزيع، 
الشر، وهذا يؤكد على الأهمية الكبرى للأخلاق

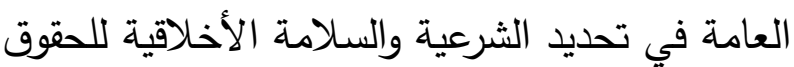
والحريات.

إن القول بأن أي تعريف للأخلاق العامة مسموح به - طالما كان يشير للدين الإسلامي في نهاية الأمر - وهذا جلي في حقيقة كون الكثير من لنئ لإني المسلمين يعتبرون دينهم مصدراً للهوية وطريقة للحياة. لذلك، أن تكون مسلمًا هو أمر يندرج تحت دئر

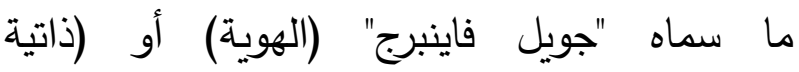
التعريف)، وهو مفهوم قياسي يتناول أفكاراً معينة

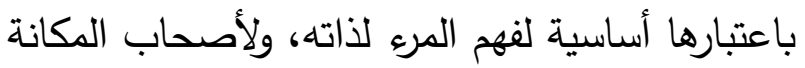
الأهم في الصورة الذاتية للمرء أو تعريفه لذاته. •

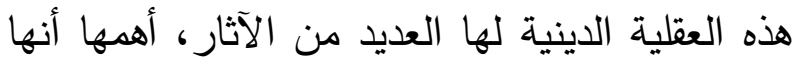
تعمل على ظهور ثقافة يقاس فيها كل شيء بمبادئ وأخلاقيات وأحكام الدين الإسلامي، حتى القوانين

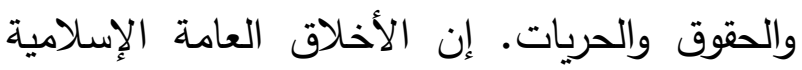

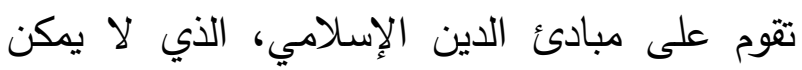

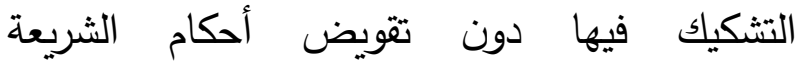
الإسلامية." ويكفي هنا أن نؤكد على أن الأخلاق

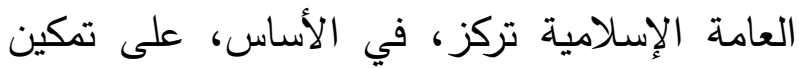
أسس الدين الإسلامي واستقامة المجتمع، وعليه فإن الإنائ تركز،

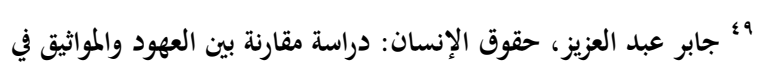

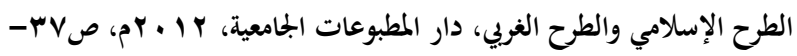

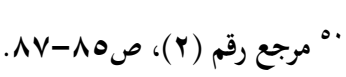

اه ثمس الدين كيلاني، مفاهيم حقوق الإنسان في الإسلام، دار الحصاد للنشر

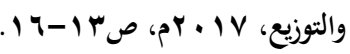

أن الأخلاق العامة يمكن أن تقوم على الأحكام

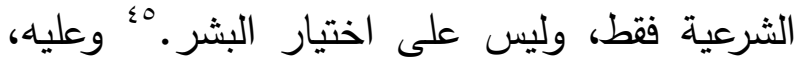
فإن معنى الأخلاق العامة يقتصر على على المسموح به

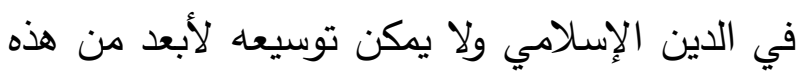

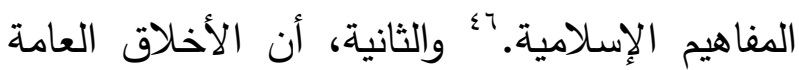

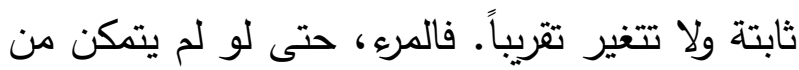
استيعاب الحكمة من وراء بعض القواعد الثرعية،

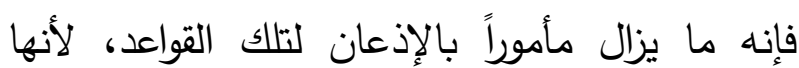

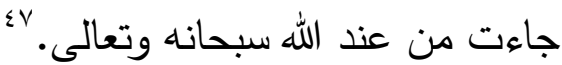

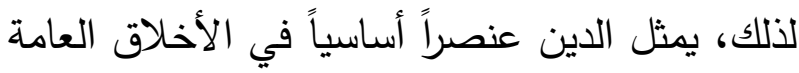
الإسلامية، إذ إن الدول والمجتمعات الإسلامية تقوم على وجوده وقوته العليا عز وجل. ولأن التشريع

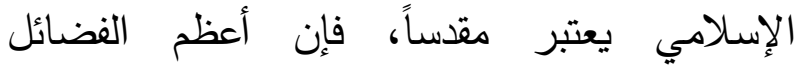
الأخلاقية وكل الخير يكمنان في اتباع قواعد الشريعة الإسلامية. وبما أن التشريع الإسلامي كامل وغير فئري

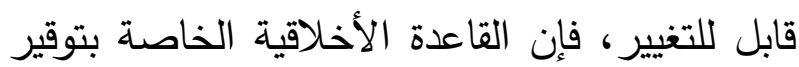

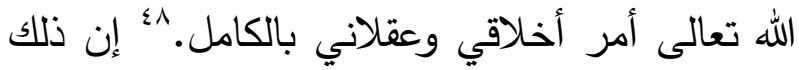

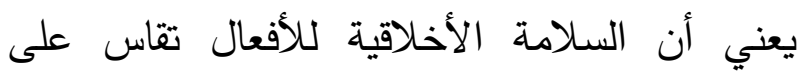

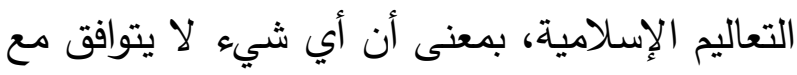

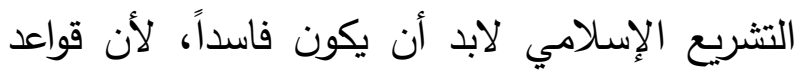

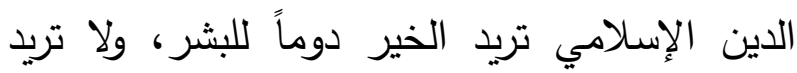

• إبراهيم عبد الله المرزوقي، حقوق الإنسان في الإسلام، الجمع الثقافي، ( ب؛ "حمد عنجريني، حقوق الإنسان بين الشريعة والقانون: نصاً ومقارنة وتطبيقاً،

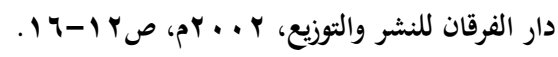

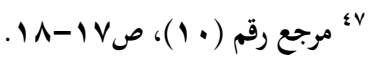

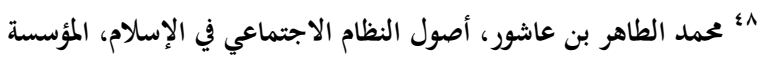

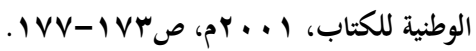


إلى حقيقة أن الإسلام مبني على قواعد وأحكام كاملة

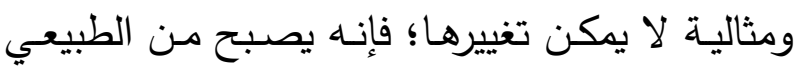
القول بأن الإسلام هو ركيزة وأساس الرؤيسة الأخلاقية للدولة الإسلامية. هذه الرؤيسة الإسلامية للأخلاق العامة في المجتمعات الإسلامية تستند إلى ثلاثتة عناصر مهمة: ا- إن الأفــراد معرضـــون للوقــوع فــي الخطـــأ، ومعـارفهم تظل دائمًا محدودة، في حين أن تعـاليم الدين الإسلامي كاملة ومثالية وغير قابلة للتغيير -

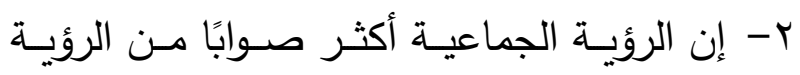
الفردية. ب- إن الواجــب الأخلاقـي، المتمثـل فـي الأمــر بـالمعروف والنهـي عـن المنكـر ، يعتبـر مـن أهـم الواجبات التي تحافظ على المجتمع. فإذا مـا تم تجميع تلك العناصر الثلاثة، فإنه يمكننا القول: إن المجتمع الإسلامي يميل إلى تقديم الإسلام

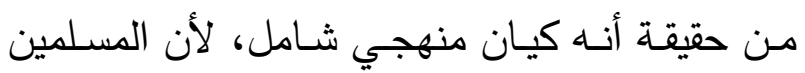

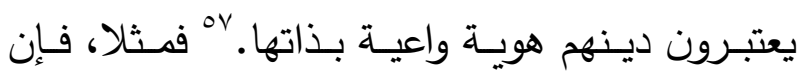

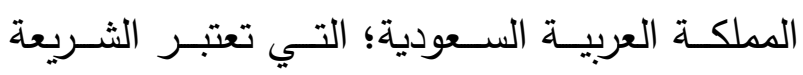
الإســلامية والقـوانين المسـتمدة منهــا مـن مقومــات المجتمع؛ تنص المـادة الأولى من النظـام الأساسـي للحكم فيها على ما يلي: "المملكة العربية السعودية دولة عربية إسـامية، ذات

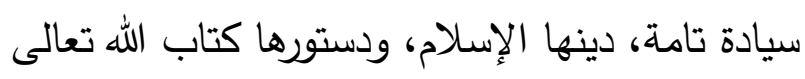

•• محمد الزحيلي، حقوق الإنسان في الإسلام، دار ابن كثير، ه . . Y م،

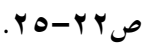

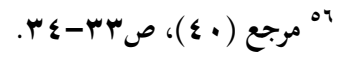

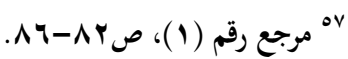

التركيز على مذهب الفردية المطلقة دون اعتبار لأهمية الدين والمجتمع أمر غير أخلاقي بطبيعته.

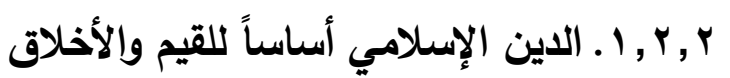
العامة في المجتمعات الإسملامية

إن معظم مواطني الدول الإسـامية يعرفون أنفسهم من خلال دينهم، بكونهم ينتمون إلى دول إسـلامية. هذه الحقيقة تدل على أن الدين الإسـلامي يلعب دوراً مهماً في تشكيل مفاهيمهم الأخلاقيـة العامـة. وهذا

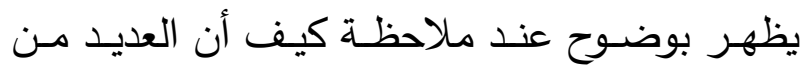
المنظمـات الإسـامية الدوليـة، مثل منظمــة التعـاون الإسـلامي، تهدف "إلى السعي الحثيث لإحياء الدور الريادي للإسلام في العالم." به وهذا يعني أن مواطني

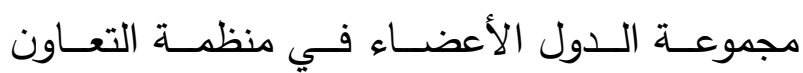
الإسـلامي (OV) دولـة) يعرفون أنفسهم بالإشـارة إلى ملى الإسـلام، ويؤكدون على ارتبـاطهم بـه وأهميتـهـ إذاً مدى إمكانية سماح الدولة للدين بأن يصبح المكون الرئيسـي في الأخـلاق العامـة للمجتمـع يتعلق بنظـرة

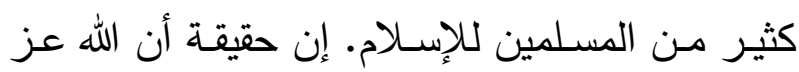
وجل هو أسـاس العقيدة الإسـامية تؤدي إلى إدراك كثير من المسلمين أن طاعة الله عز وجل أهم من

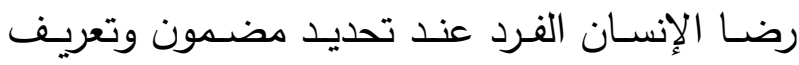
الأخلاق العامة للدولة. ؛ إله وعليـه؛ فإنـه عند تحديد مفهوم الأخـلاق العامـة في المجتمعات الإسـلامية؛ فإن التشريع الإسـلامي يجب أن يكون حجر الأساس في تقرير شرعيتها، واستتاداً

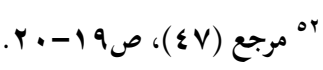

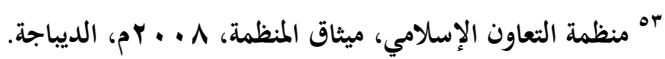

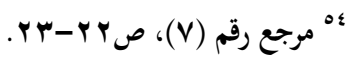


مهتمـة بالحفاظ على الحرية في مواجهة أي استبداد قانوني أو سياسي.

والسبب الثاني لـرفض المجتمعـات الإسـلامية لفكرة

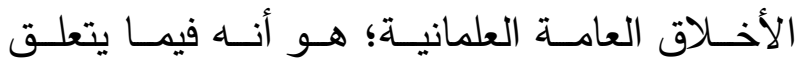
بالمسلمين؛ فإن الدين الإسلامي يشكل عاملاً أساسياً في كيفية تشكيل الأفراد والمجتمع لهوياتهم وقيمهر. فمن الصعوبة بمكان أن تطلب من المسلمين الذين

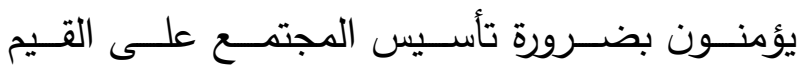
الإسـلامية، أن يفصلوا الدين عن الدولة، وذلك لأن

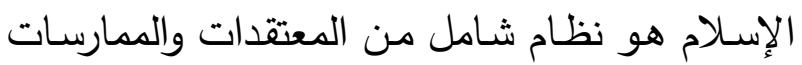

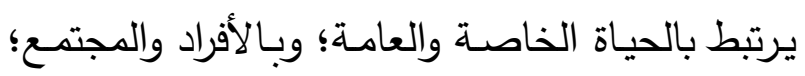
وبالحياة الدنيوية والروحية. بالتياه وهنا يجب التأكيد على أن الاهتمام بالدين الإسلامي

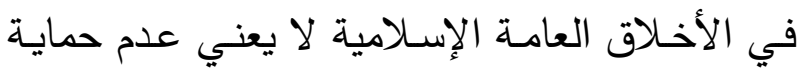

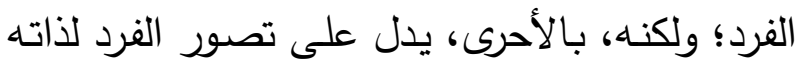

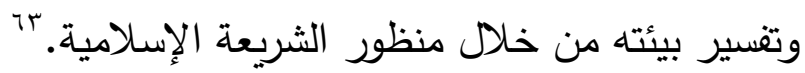
إن الهدف الرئيسي من بنـاء مفهوم الأخلاق العامـة

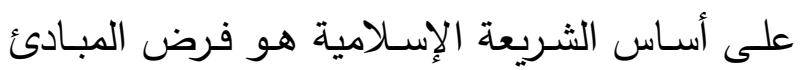

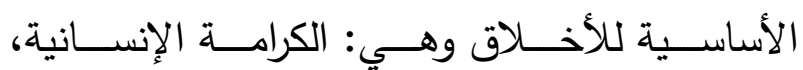
والاستقلال الذاتي، والمساواة بين الأفراد.

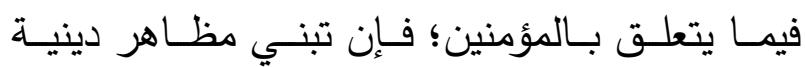
للأخلاق العامة يؤثر في كل فرد بشكل كبير ، لأنـه

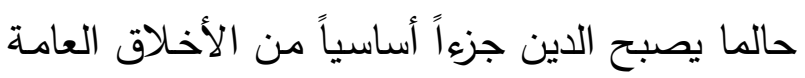

"“ عبد الله بن بيه، حوار عن بعد حقوق الإنسان في الإسلام، مكتبة

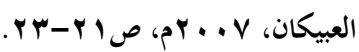

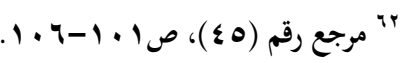

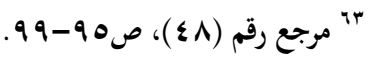

وسنة رسوله صلى الله عليه وسلم. ولغتها هي اللغة

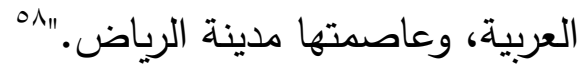
فالمادة تشير بوضوح إلى المصدرين الرئيسيين في لئي

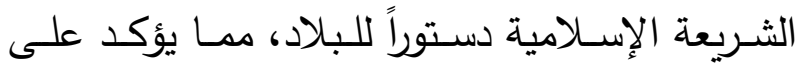

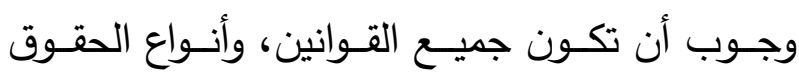

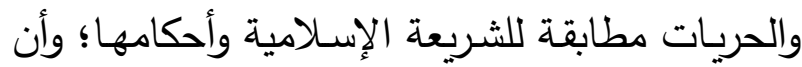
أي مخالفة للشريعة الإسلامية لا يمكن قبولها.

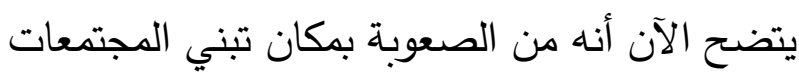

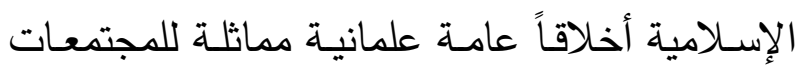
الغربية، وذلك لسببين: الأول هو أنه، عند النظر إلى الى النى

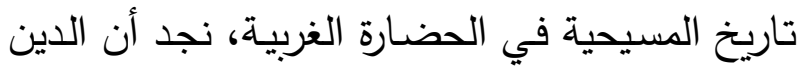
المسيحي تم استخدامه في الغالب وسيلة للاستيلاء

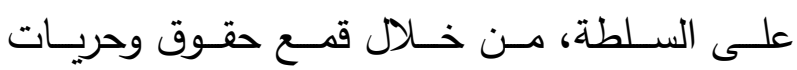
الأفراد. " وذلك بالإضـافة إلى انتشار مفهوم التتوير السابق شرحه، الذي حول التركيز من التنكير الديني

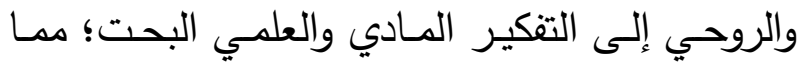

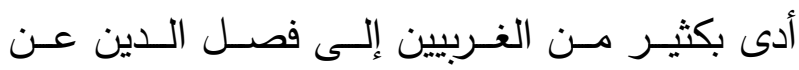

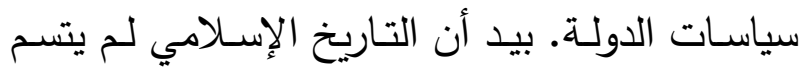

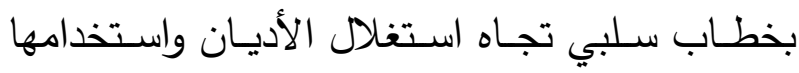
لقهع الأفراد. فقد كانت التعاليم الإسـلامية وما زالت

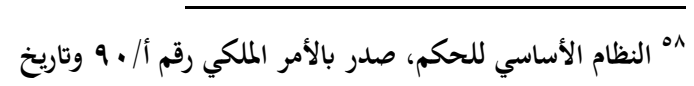

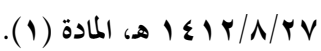

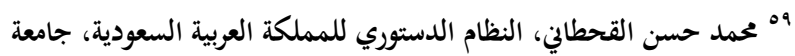

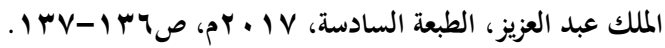

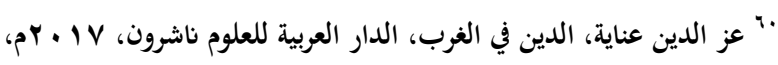

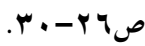


المجتمعات الإسلامية أن السلامة الأخلاقية لتحديد

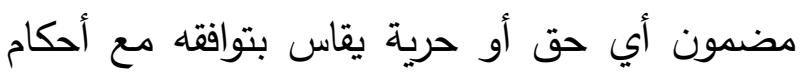

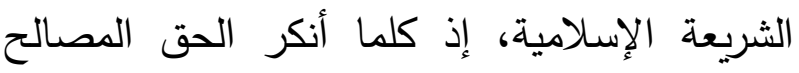
الخاصة للأفراد من أجل تدعيم شرع الله، زاد قبول الدها ذلك الحق باعتباره أخلاقياً. غير أن التطبيقات المختلفة للحقوق والحريات بين إنيا. العالم الإسلامي والغربي لا تناقض المساحة الكبيرة المشتركة بين حقوق الإنسان الدولية والثريعة الإسلامية. ففي الحقيقة، إن كلتا الأيديولوجيتين تدعم الإنسان أبرز القواعد الأخلاقية، مثل كرامة الإنسان والمساواة.

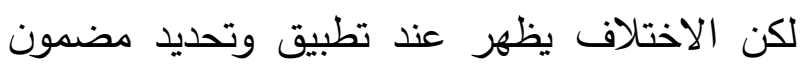

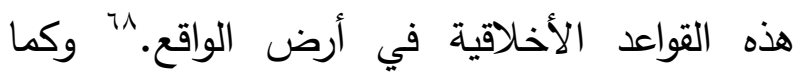

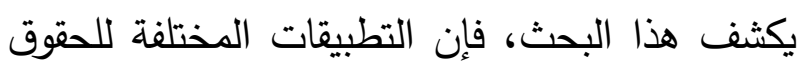

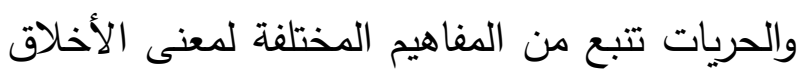
العامة للمجتمع، والتي تؤدي بالضرورة إلى معان التصني وتفسيرات مختلفة لهذه الحقوق والحريات والقوانين.

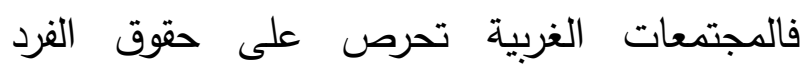
وحريته، وأن تكونا من أهم مكونات أخلاقها العامة،

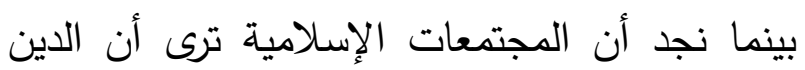
الإسلامي هو أساس الأخلاقيات العامة. لذلك كله، يمكن استتتاج السبب الرئيسي الذي يؤدي الإنياتي

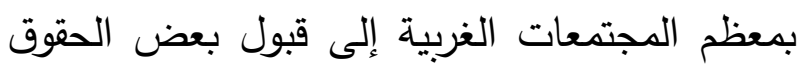

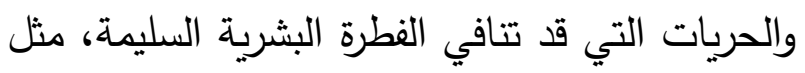

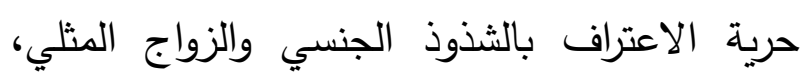

VV وائل علام، الاتفاقيات الدولية لحقوق الإنسان، دار النهضة العربية،

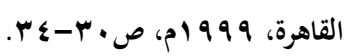
^^" محمد شريف بسيوني، حقوق الإنسان، الخجلد الأول، دار العلم للملايين،

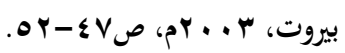

في المجتمع؛ يصبح من الصعب على أعضـاء هذا المجتمع أن ينظروا إلى الدين على أنه مجرد اعتقاد؛

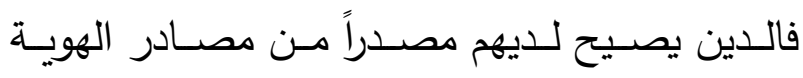

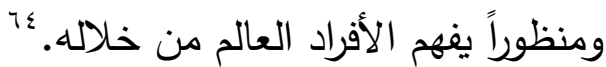

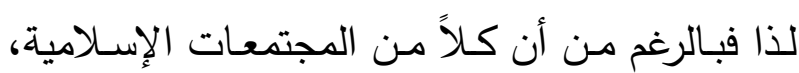
وكذلك الغربيـة، تسعى جميعها إلى حمايـة المبادئ

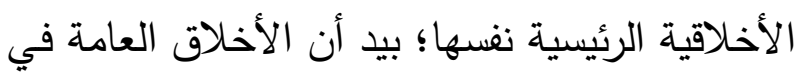

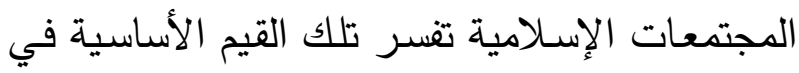

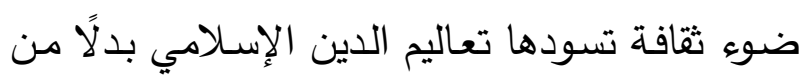

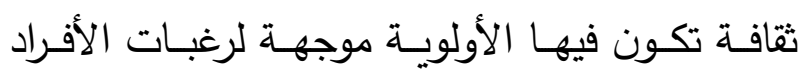

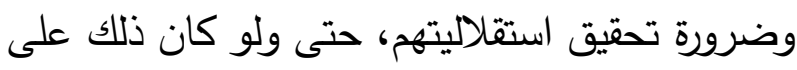
حساب مصلحة المجتمع.

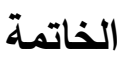

نظراً لأن الأحكام الإسلامية صالحة لكل زمان ومكان وغير قابلة للتغيير، فإن الأخلاق العامة الإنة الإسلامية تصبح أقل عرضة للتغيير عند مقارنتها

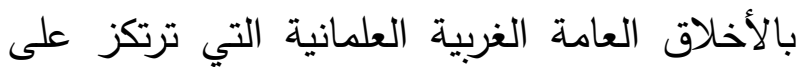

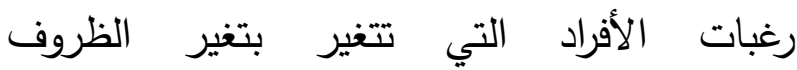
والأحوال. ب" ففي المجتمعات الغربية، يعتمد التقويم

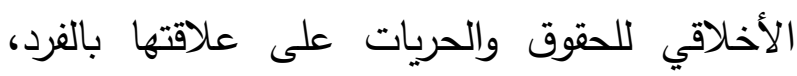
بمعنى أنه كلما كان الحق أو الحرية تمنح الفرد

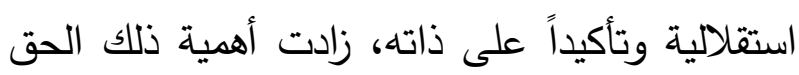

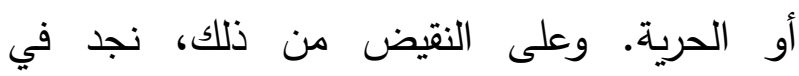

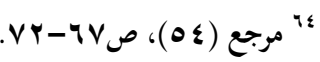
" " محمد صديق الزين علي، نحو نظام عالمي من القرآن الكريم، الدار العببية

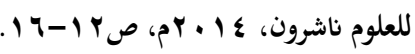
"' فوزية عبد الستار، الأخلاق في الإسلام، دار النهضة العربية للنشر

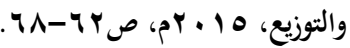


وحق المرأة في التخلي عن لباسها الشرعي. ففي كل

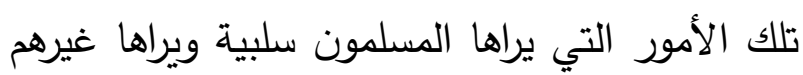

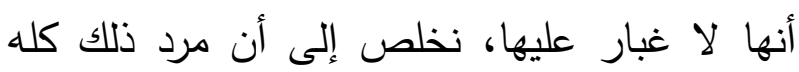

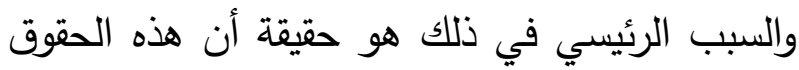
والحريات يتم تحديدها في ظل مفهوم أخلاقي قائم على مذهب الفردية المطلقة. وفي المقابل، نجد أن

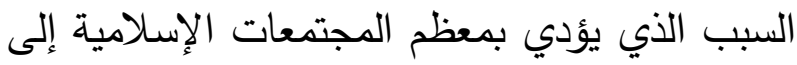

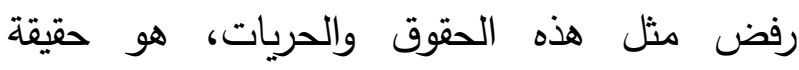

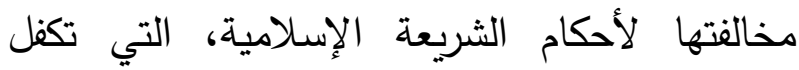

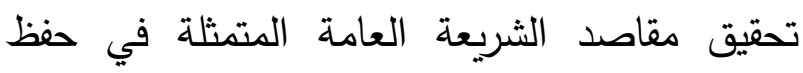

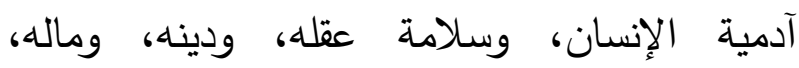
وعرضه، ونسله، بطريقة لا تنقص من كرامته ولهانه وإنسانيته. 


\title{
The Effect of Differing Concepts of Values and Public Morals in Determining the Types of Laws and Rights: A Comparative Study between Western and Islamic Countries
}

\author{
Dr. Ahmed Salahaldeen Balto \\ Assistant Professor in Public Law Department \\ Faculty of Law \\ King Abdulaziz University
}

\begin{abstract}
Islamic and Western countries, by examining some of the fundamentals agreed upon by the majority of Islamic countries on the one hand, and the fundamentals of most Western countries on the other hand. The aim is attempting at finding the reason behind the different laws and rights granted in Islamic and Western countries. The study of the general moral and value system of Islamic and Western society includes the study of all economic, cultural, social and religious factors that affect each society, meaning that the sum of these factors establishes a general moral system, through which laws and rights are applied and interpreted in practice.

While the general values and morals in most western countries are based on everything that serves the interest and independence of the human person himself, the public moral system in most Islamic countries is based on the provisions and principles of the Islamic religion. On the one hand, this study analyzes some of the historical contexts of Western countries that have significantly contributed to shifting the focus of the moral system from Christianity to humanity, secularism, and pure rationality. On the other hand, the study emphasizes the important position of the Islamic religion as the primary source of the moral system for most Islamic countries, to the extent that breaching the teachings of the Islamic religion necessarily leads to a breach of the stability of society within Islamic countries.

Therefore, this study concludes that the main reason for the difference in laws and rights between Islamic and Western countries is due to the differing values and moral systems of each of them, which greatly affect the nature and content of these laws and rights. While the Islamic moral system grants freedoms that are compatible with the teachings and principles of Islamic law and Muslim society, the Western moral system recognizes any kind of freedoms simply because it increases individual freedom and independence, even if it is at the expense of religion or society.
\end{abstract}

